\title{
Plantas medicinais usadas nos distúrbios do trato gastrintestinal no povoado Colônia Treze, Lagarto, SE, Brasil ${ }^{1}$
}

\author{
Maria Silene da Silva ${ }^{2,5}$, Angelo Roberto Antoniolli ${ }^{3}$, Josemar Sena Batista ${ }^{3}$ e Clarice Novaes da Mota ${ }^{4}$
}

\author{
Recebido em 16/02/2005. Aceito em 2/05/2006
}

\begin{abstract}
RESUMO - (Plantas medicinais usadas nos distúrbios do trato gastrintestinal no povoado colônia Treze, Lagarto, SE, Brasil). Os modelos de desenvolvimento sócio-econômicos adotados pela sociedade humana refletem diferentes formas de relacionamento com a natureza, as quais no paradigma vigente têm levado à grande perda de recursos naturais. Na esfera dessa relação, a conservação e preservação da biodiversidade da flora medicinal torna-se fundamental, pela importância que as plantas medicinais assumem como potencial genético para o desenvolvimento de novas drogas, e como acesso primário à saúde para muitas comunidades. Utilizando a abordagem etnofarmacológica na pesquisa de plantas medicinais, este trabalho teve por objetivo estudar as plantas medicinais utilizadas popularmente contra distúrbios do trato gastrintestinal no povoado Colônia Treze em Lagarto, SE, comunidade que tem o uso popular das plantas medicinais inserido em sua cultura. Sua metodologia abrangeu trabalho de campo na comunidade, adotando o método etnográfico qualitativo rápido. A amostra foi composta por líderes da comunidade, usuários de plantas e praticantes da medicina popular. Baseando-se nas indicações populares sobre o uso das plantas medicinais, selecionaram-se oito plantas que foram submetidas aos experimentos farmacológicos. As plantas testadas no Modelo de Trânsito Intestinal não produziram alteração na motilidade. Já as submetidas ao Modelo de Indução de Lesão Gástrica aguda, mostraram-se efetivas na atividade antiulcerogênica. A partir destes resultados propõem-se estratégias de desenvolvimento local para esta comunidade, que aliem a conservação da flora medicinal à melhoria de sua qualidade de vida.
\end{abstract}

Palavras-chave: plantas medicinais, conhecimento local, recursos naturais, etnofarmacologia

\begin{abstract}
Medicinal plants used for aliments of the gastro-intestinal tract at Colonia Treze village, Lagarto Municipality, Sergipe State, Brazil). Models of socioeconomic development adopted by human societies reflect different ways of relating to Nature, which, given the present paradigm, have evolved towards great natural-resource loss. Within the sphere of this relationship, both the conservation and preservation of medicinal-plant biodiversity are fundamental because of the importance of medicinal plants as genetic potential for the development of new drugs, and as the primary access to health care for many communities. Using an ethnopharmacological approach in the study of medicinal plants, this work aimed to study the medicinal plants popularly used for gastro-intestinal tract ailments, at Colonia Treze village, in Lagarto/Sergipe, since this community is culturally attuned to the use of medicinal plants. Methodology consisted of field work within the community, adopting the ethnographic Rapid Assessment Procedure. The sample was composed of community leaders, plant users and practitioners of folk medicine. Based on their indications of medicinal-plant use, eight plants were selected and subject to pharmacological experimental tests. Plants tested by the Intestinal Transit Model did not provoke alterations in motility. However, those that underwent the Acute Gastric Lesion Induction Model proved to be effective in anti-ulcerogenic activity. Based on these results, strategies for local development at the community level are proposed, which will tie the conservation of medicinal flora to improvements in life quality
\end{abstract}

Key words: medicinal plants, traditional knowledge, natural resources, ethnopharmacology

\section{Introdução}

Vários estudos, como os de Balée (1992), GómezPompa (1971; 1992), Oliveira (1992) e Posey (1987), entre outros, citados por Brasil (2001) demonstram que a biodiversidade não é só um produto da Natureza, mas também um produto da ação das sociedades e culturas humanas, em particular das sociedades tradicionais, não-industriais, que, interagindo com o meio natural, selecionam espécies de seu interesse para o cultivo e preservação, modificando o meio natural. Essas populações também detêm um grande conhecimento sobre a utilização de plantas medicinais, tendo um papel fundamental na manutenção de espécies e variedades nativas e seus sistemas de manejo. Muitas plantas ainda não foram estudadas quanto à

\footnotetext{
1 Parte da dissertação de Mestrado da primeira Autora, defendida pelo PRODEMA/Universidade Federal de Sergipe

2 Fundação Universidade Estadual de Alagoas, FUNESA e Centro Federal de Educação Tecnológica de Sergipe, UNED Lagarto, Rodovia Lourival Batista s/n, Povoado Carro Quebrado, 49400-000 Lagarto, SE, Brasil

3 Universidade Federal de Sergipe, Departamento de Fisiologia, Av. Marechal Rondon s/n, Rosa Elze, 49100-000 São Cristóvão, SE, Brasil

4 Universidade Federal de Alagoas, UFAL, Rua Adalberto Aranha 60/304, 20540-000 Rio de Janeiro, RJ, Brasil

5 Autor para correspondência: mariasilene@yahoo.com.br
} 
sua eficácia terapêutica, mas o conhecimento tradicional sobre as mesmas já as tornou parte integrante da prática médica popular, sendo utilizadas por até $90 \%$ da população economicamente carente do Nordeste, para a cura de seus problemas de saúde (Matos 2002). "Ao redor de 20 mil plantas são utilizadas no mundo pelas medicinas tradicionais, destas somente 5 mil foram estudadas como fontes potenciais de substâncias de uso médico" (Lévêque 1999).

Para fins deste trabalho, conhecimento tradicional (saber popular) é definido "como o conjunto de saberes e saber-fazer a respeito do mundo natural e sobrenatural transmitido oralmente, de geração em geração". Esse conhecimento é transmitido em todos os níveis da vida diária e não apenas no formal. A sua comunicação por meio da oralidade é uma das diferenças que o separa do científico, que é transmitido por meio da escrita. Nesse sentido o conhecimento tradicional somente pode ser interpretado dentro do contexto cultural em que foi gerado (Brasil 2001).

A maior parte da flora medicinal é ainda desconhecida químico/farmacologicamente, e o saber tradicional a ela associado existe predominantemente em países em desenvolvimento. O Brasil está incluído entre as doze nações que abrigam $70 \%$ da biodiversidade do planeta. À importância, de âmbito global, da conservação dessa biodiversidade, soma-se sua relevância para a economia do país (Brasil 2002). Destaca-se, porém, que o Brasil não é apenas rico em diversidade de recursos genéticos. É também um país rico em culturas, formadas por indivíduos que tiveram e têm que tirar a vida com as mãos, manejando seu meio ambiente, conhecendo em detalhes e no todo suas conexões e inter-relações. O futuro da biodiversidade depende dos modos de desenvolvimento que serão privilegiados pelas sociedades humanas e da evolução dos circuitos econômicos. O respeito ao meio ambiente e ao modus vivendi de comunidades tradicionais, tornam-se fundamentais para o desenvolvimento sustentável e à manutenção da sociobiodiversidade (Lévêque 1999; Elizabetsky 2003).

Viertler (1999) destaca que no atual contexto mundial torna-se fundamental garantir a sobrevivência dos recursos necessários à vida no planeta, através da criação de manejos inteligentes, planejamentos racionais, ou modalidades de "desenvolvimentos sustentados" que viabilizem a continuidade de um número de diversidade das formas de vida no planeta, ressaltando que a idéia de "desenvolvimento sustentável" não é somente um conceito de natureza científica, mas antes uma condição desejada de equilíbrios biossociais, tornando-se fundamental uma compreensão adequada da relação homem-ambiente "aceitando-se que os representantes da espécie humana como um todo, cria parte do seu ambiente (...) e que nessa interação dinâmica entre homem e ambiente, existe a atuação de um referencial da maior importância metodológica: a 'Cultura' do grupo humano focalizado".

Nesse contexto, servindo de mediadora entre culturas diversas, a abordagem etnofarmacológica como estratégia na investigação de plantas medicinais tem se mostrado de grande eficácia para a descoberta de novos fármacos. A etnofarmacologia está inserida no contexto da Etnobiologia que é o estudo do conhecimento e das conceituações desenvolvidas por qualquer cultura sobre os seres vivos e os fenômenos biológicos, tratando de práticas médicas, das relações entre as populações humanas e as plantas medicinais, ou remédios usados em sistemas tradicionais de medicina (Elisabetsky 2001; Albuquerque 2005).

Combinando as informações populares sobre a flora medicinal, adquiridas junto aos usuários, (comunidades e especialistas tradicionais), com estudos químico/ farmacológicos, essa abordagem permite a formulação de hipóteses quanto à atividade farmacológica e à substância ativa responsável pelas ações terapêuticas relatadas, "já que seu uso tradicional pode ser encarado como uma pré-triagem quanto à utilidade terapêutica em humanos (não desconsiderando a possível toxicidade dessas plantas), sendo particularmente útil no caso de doenças cuja fisiopatologia não é bem conhecida" (Elisabetsky 2001).

Várias plantas medicinais têm sido usadas para o tratamento de distúrbios gastrintestinais. A primeira droga sistematicamente efetiva contra úlceras gástricas, a carbenoxolone, foi descoberta como resultado de pesquisas com Glycyrrhiza glabra (Alcaçuz), comumente usada pelo indígenas (Aktar \& Munir 1989). Um ponto importante a ser analisado quando se decide pelo trabalho aplicado com uma dada classe terapêutica é a incidência da morbidade na população; este tipo de dado reflete o binômio: importância em saúde pública e mercado local e mundial para a substância potencialmente útil na patologia. Ainda não existe no mercado uma droga que leve à remissão completa das úlceras gastroduodenais (Hiruma-Lima 2000).

Dados recentes na literatura demonstram a grande variedade de substâncias químicas isoladas de plantas que apresentaram atividade antiulcerogênica e contra distúrbios do trato gastrintestinal, como, por exemplo, 
o trabalho de Hiruma-Lima (2002) que isolou a transdesidrocrotonina e trans-crotonina de Croton cajucara Benth (sacaca), e o de Rao et al. (1997) que isolaram o ternatin de Egletes viscosa (macela). A pesquisa por princípios ativos obtidos de plantas medicinais pode prover a descoberta de novos compostos, úteis para o desenvolvimento de novas drogas, e a preços mais acessíveis para a maioria da população.

Este trabalho teve por objetivo estudar as plantas medicinais utilizadas contra distúrbios do trato gastrintestinal pela medicina popular do Povoado Colônia Treze em Lagarto, Estado de Sergipe, visando o conhecimento científico dos seus efeitos, através de ensaios farmacológicos, bem como uma compreensão da relação da comunidade com o ambiente.

\section{Materiais e métodos}

Área de estudo - O estudo foi realizado no Povoado Colônia Treze em Lagarto, Estado de Sergipe, região Nordeste do Brasil. Este município está situado na porção Sul do estado, distante $78 \mathrm{~km}$ da capital, Aracaju. Apresenta clima de transição semi-árido dominando a maior parte de suas terras na faixa oeste do município, onde se localiza o povoado em estudo, com uma estreita faixa a oeste caracterizada pelo clima subúmido (Lisboa 2001). Possui 83.334 habitantes, sendo que praticamente metade reside na zona rural e a outra na zona urbana (Brasil 2000).

O povoado Colônia Treze possui 7.514 habitantes, com 1.727 famílias cadastradas pelos Agentes Comunitários de Saúde do Município (Lagarto 2002). O início de seu povoamento deu-se na década de 50, a partir de uma política do Governo Federal que possibilitava aos proprietários das terras o recebimento de financiamentos, se doassem parte de sua área para colonos. Com a criação da Cooperativa Mista dos Agricultores do Treze (COOPERTREZE), em 1962, novas terras foram compradas, abrindo-se as primeiras colônias, que foram denominadas de "pistas" (Lisboa 2001). Atualmente, divide-se em pequenas localidades que apresentam sítios e fazendas, cuja atividade predominante é a agricultura. Em parte da área denominada Pista Principal (Rodovia Estadual Lourival Batista), surgem características de zona urbana com ruas asfaltadas, praças e a área comercial que está se expandindo no Povoado, correspondendo ao centro da Colônia Treze.

Lagarto caracteriza-se pelo domínio quase absoluto de propriedades particulares individuais, administradas pelos seus donos, destacando-se a importância da COOPERTREZE na territorialização de povoados como a Colônia Treze, para persistência da agricultura familiar dessa área (Lisboa 2001). Observou-se uma estreita relação entre a prática da agricultura familiar e o cultivo e preservação das plantas medicinais no povoado.

Um levantamento feito pelo projeto RADAMBRASIL, entre 1977 e 1981 apud Brasil (1995) quantificou as diferentes formações vegetais do Estado de Sergipe, sendo 17,2\% de seu território coberto por caatingas, $15,1 \%$ de outras formações vegetais, e o restante $67,7 \%$ correspondentes à área antropizada do Estado. Esse contexto reflete-se na vegetação da região estudada. Em Sergipe, a área do Agreste, deveria apresentar caatinga com predomínio da floresta xerófila decídua, caso o uso do solo para fins pecuários não a tivesse reduzido a manchas sobre elevações e nascentes, assim como nas margens de nascentes e cursos de água, como se observa em Lagarto, onde $80 \%$ das terras estão ocupadas por pastagens. A ocorrência dessa vegetação da caatinga está ligada a fatores edafoclimáticos, ou seja, à existência de solos profundos, com textura para armazenar a água das chuvas e não apenas a pluviosidade do Agreste (Brasil 1995; Lisboa, 2001). Áreas de vegetação primária na Colônia Treze são restritas a pequenos fragmentos, sendo a maior parte utilizada para a agricultura de subsistência. Nas margens dos riachos ainda são encontradas algumas faixas de vegetação que guardam muitas espécies, inclusive medicinais, entre elas a aroeira da praia (Schinus terebinthifolius Raddi) e babatenã (Abarema cochliocarpos (Gomes) Barneby \& Grimes), por exemplo.

Diante deste quadro natural de pouca ou nenhuma vegetação nativa questionamos: $\mathrm{O}$ que e como se mantém o fornecimento da matéria médica vegetal, elemento fundamental para a prática da medicina popular no povoado? Nesse contexto, a escolha desse local para pesquisa deveu-se ao fato de se tratar de uma comunidade que tem a prática da medicina popular fortemente relacionada com sua cultura, tendo como principal matéria médica plantas medicinais, cultivada em suas propriedades e sendo, muitas vezes, o único recurso terapêutico disponível.

Pesquisa de campo com informantes da comunidade - A coleta de dados foi feita utilizando-se o método etnográfico qualitativo rápido (Rapid Assessment Procedure - RAP), de acordo com Scrimshaw \& Hurtado (1987), constituído por: caracterização da 
população-alvo; trabalho de campo com informantes da comunidade e análise das representações sociais dos atores sociais. O RAP consiste numa proposta de método rápido de estudo e avaliação da Assistência Primária à Saúde. Trata-se na realidade, de uma simplificação do método antropológico, aplicando-o aos problemas, ações e programas de saúde (Minayo 1991; Deslandes 1997). A escolha desse método deveu-se ao fato de possibilitar estudar não só o conhecimento da planta, mas também do indivíduo que usa a planta, visto que esse uso está intrinsecamente relacionado com o saber popular, com a dimensão de uma cultura que estabelece uma íntima relação com a natureza (Carrara 1995). Como parte da metodologia, as visitas periódicas à comunidade foram realizadas regularmente para a coleta de dados através da aplicação do instrumental de pesquisa, ocorridas no período de julho/2001 a dezembro/2002.

Nesta etapa da pesquisa foi realizado o levantamento sociológico de informações populares sobre o uso das plantas medicinais, com ênfase naquelas de provável ação contra os distúrbios do trato gastrintestinal, com a aplicação de entrevistas e coleta de espécimes botânicas. Foram utilizadas entrevistas roteirizadas de perguntas abertas, parcialmente estruturadas, e questionário. As entrevistas foram cuidadosamente registradas num diário de campo, sendo que a maioria delas foi também gravada com prévia autorização dos informantes. Paralelo às entrevistas foi aplicado o questionário em formulário próprio, no qual foram destacados os nomes populares das plantas, contra-indicações, quanto se toma, que parte da planta é utilizada, como se usa e como se prepara. Essa escolha deveu-se pela necessidade de obtenção de respostas precisas sobre vias de administração e modos de preparo que possam dar indicação de que tipos de compostos possam estar na preparação, tornando possível estabelecer relações com os ensaios farmacológicos.

A amostra foi não-probabilística, por conveniência e intencional. Sendo composta por dezoito informantes. As variáveis analisadas foram: nível sócio-econômico, origem do conhecimento, sistema de crenças, grau de instrução, idade dos usuários e praticantes da medicina popular e local de residência.

A seleção de plantas para os testes farmacológicos obedeceu aos seguintes critérios: (i) as informações prestadas pelos principais informantes, as quais foram cuidadosamente comparadas, selecionando-se as plantas com o maior número de indicações; (ii) verificação da disponibilidade da planta na comunidade.
A partir das informações adquiridas na comunidade sobre o uso popular das plantas medicinais com potencial ação contra distúrbios do trato gastrintestinal, selecionou-se as espécies de plantas que foram submetidas aos ensaios farmacológicos. Todas as plantas foram coletadas no Povoado Colônia Treze em Lagarto, SE. Algumas amostras foram utilizadas para preparar exsicatas e outras para a preparação de extratos em laboratório.

Foi feita a identificação botânica das plantas selecionadas para estudo e suas exsicatas estão depositadas no Herbário da Universidade Federal de Sergipe. Kalanchoe brasiliensis L. foi identificada pelo Dr. Joachim Thiede, da Universität Hamburg, Luffa cylindrica L. Roem foi identificada pelo Dr. Michael Nee do New York Botanic Garden, Abarema cochliocarpos (Gomes) Barneby \& Grimes identificada pela Dra. Chistine Niezgoda do Field Museum of Natural History, Alternanthera brasiliana L. pelo Dr. Antonio Furlan da Universidade Estadual de São Paulo, Vernonia condensata Baker pelo Dr. Roberto L. Esteves da Universidade Federal Fluminense e Ocimum gratissimum L. pelo Dr. Raymond M. Harley da Universidade Estadual de Feira de Santana e Royal Botanic Garden Kew. Foram identificadas com o auxílio da literatura Brassica oleraceae L. e Cocus nucifera L. por não terem sido encontradas amostras com ramos férteis, como também as demais plantas não selecionadas para estudo.

Experimentos farmacológicos - Foram preparados extratos aquosos brutos das plantas selecionadas para estudo, com a parte da planta a ser utilizada, através dos quais foram realizados testes farmacológicos préclínicos, utilizando-se o Modelo de Indução de Úlcera Aguda por Álcool (Singh \& Majundar 1999), para as plantas indicadas contra úlcera, e o Modelo do Trânsito Intestinal (Takemori et al. 1969) para as plantas indicadas contra distúrbios de motilidade. Estes procedimentos foram realizados nos Laboratórios do Departamento de Fisiologia da Universidade Federal de Sergipe. Os dados foram testados pela análise de variância (ANOVA) uma via seguido pelo teste de Dunnett.

\section{Resultados e discussão}

A medicina popular no povoado Colônia Treze - A prática da medicina popular envolve um grupo de indivíduos bastante heterogêneo. Os nossos informantes são moradores das localidades Luís Freire (1), Cova da Onça (2), Pista Principal (4), Pista da 
Granja (1), Piçarreira de Cima (4) e Piçarreira de Baixo (6). Os informantes foram divididos em três categorias: a) Lideranças da comunidade, representadas pela Pastoral da Criança da Igreja Católica e Agentes de Saúde; b) Usuários de plantas, sendo donas de casa e doentes de úlcera e gastrite; c) Praticantes da medicina popular, garrafeiro, parteira, rezadores, e umbandistas.

A Pastoral da Criança possui um papel importante na disseminação de um conhecimento exógeno sobre as plantas medicinais na comunidade. $\mathrm{O}$ trabalho é feito de forma voluntária, e conta com a participação ativa de agentes de saúde e donas de casa do povoado. Seu principal objetivo é a prestação de assistência a crianças de 0 a 6 anos e a gestantes nas localidades economicamente menos privilegiadas. Atendem a cerca de 120 famílias. De acordo com uma das líderes da Pastoral e Agente de Saúde, trabalhando no Posto de Saúde da área central do povoado, é prestada assistência a nove comunidades do povoado. Em cinco destas a Pastoral trabalha juntamente com os Agentes de Saúde. São apenas seis voluntárias para 120 famílias. Realizam o trabalho nos finais de semana e o têm como um lazer.

O conhecimento sobre plantas medicinais é oriundo de cursos prestados pela Empresa Brasileira de Pesquisa Agropecuária, pelo Programa de Saúde da Família e pela própria Pastoral. Esse conhecimento é transmitido às comunidades através de reuniões feitas para explicar a utilidade das plantas e seu modo de uso. Também fazem remédios das plantas, principalmente xarope contra gripe, infecções respiratórias, dores e inflamação, que são distribuídos pela comunidade. Além disso, trabalham com alimentação alternativa. As plantas disseminadas pela Pastoral são cultivadas pelas próprias donas de casa, em seus quintais e também em uma horta medicinal mantida pela pastoral. Segundo uma dona de casa, voluntária da Pastoral e moradora dessa comunidade, diarréia e gripe são as doenças mais combatidas.

Nessa comunidade existem vários rezadores que trabalham com plantas medicinais, mas, no entanto, não foi observado contato entre esses dois grupos de trabalho. Quanto aos moradores do povoado, de uma forma geral, não fazem distinção entre eles, pois recorrem tanto aos rezadores quanto à pastoral na procura de solução para seus problemas de saúde.

As donas-de-casa também desempenham um papel importante na disseminação do conhecimento e no cultivo das plantas medicinais de seu interesse, relacionadas à cura de problemas de saúde mais corriqueiros, especialmente os que enfrentaram ou ainda enfrentam relacionados às doenças dos filhos.
Conhecem com detalhes o preparo de chás e xaropes contra infecções respiratórias. Deixaram claro que não rezam e não receitam plantas. Afirmaram ter aprendido sobre plantas através de informações passadas por vizinhos ou familiares.

"Eu fazia o chá, uma pessoa ensinava. Chegava na casa de um pegava planta. Um filho doente. Não ia pro médico toda hora. Antes de buscar o da farmácia dá o de casa" (D.Z., abril de 2002).

"Com o pessoal, uns e outros. O pessoal foi dizendo e a gente foi aprendendo"(D.E., junho 2002).

Em geral, o poder de cura foi atribuído à própria planta. "Cura porque todo remédio é com erva. Aquele chá que faz serve".

Apesar do cenário ambiental desfavorável, no que diz respeito aos poucos acessos de vegetação primária de plantas medicinais, catalogou-se um grande número de espécies cultivadas e utilizadas para diversos fins por praticantes e usuários da medicina popular.

Observou-se que as áreas ao redor dos domicílios, definidas como quintais ou terreiros (Amoroso 2002), são os locais em que as plantas são cuidadosamente cultivadas. Eles apresentam um mosaico de diferentes ambientes. Servem à criação de animais domésticos, cultivo de plantas ornamentais, frutíferas e medicinais. Além disso, é um local de intenso convívio social, e de estreitamento de laços de amizade através da circulação de seus produtos entre a vizinhança. Amoroso (2002), destacando o papel dos quintais para as comunidades tradicionais, enfatiza que o mesmo, por serem locais de acesso imediato, é para onde se transplantam elementos úteis da vegetação nativa, que, assim "ficam mais à mão". É também ali que se mantêm mudas de algumas plantas trazidas das roças, enquanto se aguarda a próxima estação, contribuindo tanto para manter vivas as tradições locais como para disseminar germoplasma de interesse da população. Os quintais dos praticantes da medicina popular no povoado são especialmente ricos em flora medicinal, que é cultivada paralela às suas culturas de subsistência. Sendo grandes conhecedores da utilidade e modo de uso das plantas, cultivam muitas espécies diferentes que usam no preparo de seus remédios ou em suas rezas. Quando necessitam, buscam espécies em locais mais distantes, ou trazem mudas dessas regiões para cultivarem em seus quintais.

Valle (2002) aponta que as plantas cultivadas são resultadas de um estreito processo co-evolutivo entre espécie humana e um grupo de espécies vegetais que resultou em uma estreita dependência. Destaca 
também que o conhecimento tecnológico para coletar e manter acessos desses recursos genéticos mostrou-se caro, insuficiente e principalmente inócuo para objetivos utilitários. Compreendeu-se então que os recursos genéticos dessas plantas estão imersos em uma matriz de conhecimento popular imprescindível à sua utilização e impossível de ser reproduzida artificialmente. Nota-se, portanto, a importância do conhecimento tradicional sobre a eficácia da planta medicinal para a promoção do seu cultivo e preservação.

Quanto ao conhecimento sobre úlcera e gastrite, sabem a que se refere, não conhecendo as causas, tendo pessoas vizinhas que sofreram de úlcera e já se submeteram à cirurgia. Não conhecem plantas específicas para essa enfermidade. $\mathrm{O}$ contato com doentes de úlcera não foi realizado. As pessoas que foram citadas pelos informantes, algumas já haviam sido curadas com plantas medicinais, outras, porém, já haviam se submetido à cirurgia e usavam medicamentos alopáticos. Observou-se existir constrangimento em admitir que tenham úlcera. Era sempre algum familiar ou vizinho que apontavam os doentes, mas o contato era dificultado. Em outros casos não se admitia que tivesse casos dessa doença na família, quando era conhecida a existência. Quanto à gastrite isso não ocorreu. Não foi observado nenhum tipo de constrangimento por parte das entrevistadas. Tanto que suas respostas iam além das perguntas formuladas, falando livremente sobre os sintomas que sofriam e os exames que haviam realizado. Foi mantido contato com três mulheres do povoado. Possuem faixa etária entre 30 a 50 anos, moram na Piçarreira de Baixo (2) e na Cova da Onça (1), são donas de casa, trabalham na roça e cuidam da família. Todas possuem gastrite nervosa há muito tempo. Fizeram endoscopia para diagnosticar o problema. Atribuíram à causa a "pessoa passar da hora da comida e não se alimentar direito" Não conhecem ninguém que foi curado.

$\mathrm{O}$ alto preço dos medicamentos alopáticos indicados contra gastrite torna-os inacessíveis para as informantes. Isso associado aos poucos resultados significativos obtidos desestimulou seu uso. Daí, a planta medicinal cultivada em seus próprios terreiros, surgir como alternativa de fácil acesso e baixo custo para o alívio de seus problemas. $\mathrm{O}$ aprendizado sobre a utilidade das plantas surgiu através de informações que são repassadas entre os próprios doentes ou indicadas por outras pessoas. Dessa mesma forma adquirem as plantas e as cultivam. Experimentam várias espécies de plantas. Cada informante utiliza em média três plantas diferentes que vão se alternando no tratamento. No total foram citadas sete: Maxixão (Luffa cilyndrica L. Roem); babosa (Aloe vera (L.) Burm. f.); couve (Brassica oleracea L); canudinho (Hyptis pectinata (L.) Poit.); cidreira (Lippia sp.); erva-doce (Pimpinella anisum L.); folha da costa (Kalanchoe brasiliensis L.).

Isso remete ao pensamento de Carrara (1995) quando explicita: "consideramos a medicina popular um saber construído e exercido por usuários e praticantes de origem camponesa, que transmitem, quase sempre, através da tradição oral, um conjunto de categorias nosológicas, uma matéria médica, uma prática, uma filosofia e uma semiologia específicas, constitutivas de um pensamento médico, também específico, que, apesar de seus efetivos cuidados médicos jamais terem sido computados em estatísticas médicas, desde a era pré-colombiana, sempre teve papel significativo no tratamento de doenças que afligem as classes subalternas da sociedade brasileira".

Um depoimento dado por uma das informantes, da Pastoral da Criança, evidencia a visão de parte da comunidade sobre estes praticantes da medicina popular (em especial os umbandistas).

"Eu mesmo vejo o rezador como uma seita, sou uma descrente (...). As pessoas procuram o rezador muitas vezes por falta de condição de comprar o medicamento, ou na maioria das vezes, também acreditam às vezes mais no rezador do que no médico."

Quanto à quais pessoas procuram o rezador, responde:

"Eu acho que a maioria é pessoas carentes, mas existem pessoas que podiam pagar consultas e procuram o rezador. Existe também o rezador que explora, que são caros e têm pessoas que têm dinheiro e que procuram".

Neste trabalho foram consideradas praticantes, as pessoas que conhecem plantas medicinais, receitam e as que utilizam para rezar tanto em males físicos quanto espirituais. Essa parte da amostra foi composta por rezadores, umbandistas, parteira e garrafeiro. Estes praticantes da medicina popular têm como atividade econômica predominante a agricultura. A maioria são pessoas economicamente menos favorecidas, que não possuem grau de instrução da educação formal. São em sua maioria pessoas de meia-idade, entre 40 e 60 anos, porém existe um rezador mais jovem, com 30 anos. A maioria dos praticantes atua na medicina popular entre 15 e 30 anos, sendo quase todos naturais do próprio povoado. 
A origem do conhecimento sobre plantas medicinais é atribuída às mais diferentes formas. Os rezadores e umbandistas, em sua maioria, afirmaram ter aprendido por si próprio ou através de divindades que lhes aparecem em sonhos. Apenas uma rezadeira afirmou ter aprendido com seu marido, e outro rezador afirmou ter aprendido conversando com outras pessoas porque não sabia ler. Observou-se que alguns deles herdaram a profissão do pai, apesar de não dizerem isso de forma direta.

Não demonstraram tratar de uma classe de doença em especial, mas sim das várias enfermidades que acometiam seus pacientes, seja ela física ou espiritual. Nas doenças que se acredita ter origem espiritual associa a reza ou a simpatia com as diversas plantas medicinais conhecidas. Apenas a parteira tem maior conhecimento de plantas que curam problemas femininos, relacionados ao ciclo menstrual, parto e aborto.

Todos demonstraram bastante responsabilidade no trato com seus pacientes, encaminhando ao médico quando necessário. As pessoas que procuram atendimento não pertencem a uma classe social específica; algumas com recursos financeiros, em certos casos, procuram os praticantes da medicina popular; outras, que não possuem recursos financeiros, também os procuram para conversar e pedir conselhos. A faixa etária de seus pacientes é variável. Recebem pessoas de todas as idades para se consultar. Atendem pessoas da própria Colônia Treze, de povoados circunvizinhos, e de cidades como Lagarto, Boquim, Salgado, Campo do Brito, Simão Dias, Arauá, dentre outras.

Nas visitas a comunidade foram observadas várias pessoas à procura dos rezadores. Os atendimentos são feitos em particular, e em local reservado. Muitos deles, especialmente os umbandistas, mantêm dentro de sua residência ou anexa a ela, um local próprio para suas consultas. Lá ficam imagens de santos da igreja católica, quadros de Padre Cícero e Frei Damião, juntamente com as divindades da umbanda e tambores para rituais. Um deles mantém praticamente uma casa inteira para seus atendimentos. Nos vários cômodos guarda as plantas medicinais juntamente com seus trabalhos de umbanda.

Quanto à atualização dos conhecimentos, a maioria afirmou que não conversa com ninguém para aprender mais sobre plantas, e nem com os outros rezadores. Afirmam serem as entidades que vêm através dos sonhos que os ensinam. Apenas um deles afirmou que seu aprendizado era conversando com outras pessoas.
Sobre o poder de cura das plantas, a maioria atribuiu esse poder a Deus. E associaram a cura à fé que a pessoa tem. Declararam que a planta cura porque é uma medicina e que quase todas as doenças são curadas com plantas. Outros também destacaram a importância do resguardo (regime) para a cura.

Ao serem indagados sobre o que era e quais as causas de úlceras e gastrites, a grande maioria demonstrou conhecimento do assunto, como também de plantas utilizadas contra essas doenças. Afirmaram que úlcera é uma doença que o indivíduo cria na boca (início) do estambo (estômago), e fica doendo e queimando; acreditam que é proveniente da gastrite, que se ficar velha, vira úlcera. Associam-na também ao câncer. Atribuíram as causas ao cigarro e à bebida alcoólica. Outros acreditavam estar relacionada à ingestão de alimentos quentes juntamente com água fria.

Indagados sobre se conheciam alguém que foi curado dessas doenças, alguns afirmaram não ter remédio para curar, só para melhorar, outros, porém, afirmaram ter pessoas curadas através das plantas que eles receitaram.

Um deles afirmou que contra a úlcera planta só cura no início, "se tiver passada (estágio avançado da doença) só com operação (cirurgia)". E não conhece ninguém que foi curado. Disse que só o médico cura. Alguns afirmaram terem curado pessoas com úlcera com plantas que eles receitaram, sendo elas a Babatenã (Abarema cochliocarpos Gomes Barneby \& Grimes), maxixão verde (Luffa cylindrica L. Roem), babosa (Aloe vera (L.) Burm. f.) e couve (Brassica oleracea L.).

Todos demonstraram grande conhecimento de espécies de plantas indicadas para as mais diferentes enfermidades, das partes da planta utilizada e de suas formas de uso.

A maioria dos informantes conhece alguém que tenha gastrite, seja algum conhecido ou pessoas da própria família. Tendo sido citados sete casos. Quanto a casos de úlcera, observou-se que existiu receio de alguns informantes em admitir casos da doença na família. Outros, porém, admitiram. Foram citados oito casos de úlcera.

Ao todo, os informantes indicaram um total de 95 plantas para as mais diversas enfermidades, sendo que destas, 14 foram indicadas contra úlcera e gastrite e 11 plantas foram indicadas contra distúrbios de motilidade intestinal, citados como: dor de barriga, comida que faz mal, má-digestão, prisão de ventre, disenteria e inquitação (Tab. 1, 2).

As plantas medicinais são utilizadas pelos praticantes e usuários da medicina popular 
principalmente através de chás, xaropes, garrafadas, o suco e o sumo da planta. Os chás são quase sempre preparados por decocção das partes das plantas. Os informantes acreditam que a planta só tem utilidade se for cozida. Uma das usuárias comentou que um médico havia lhe explicado que o ideal era fazer os chás por infusão, explicou-lhe o procedimento, mas ela não acreditava que o chá feito por infusão fizesse efeito. Citam, porém, que algumas plantas devem ser preparadas por infusão, senão o pé da planta morre. Por exemplo, o caso da arruda (Ruta graveolens L.) e manjericão (Ocimum basilicum L.).

Os xaropes são preparações utilizadas especialmente contra gripe. Utilizam várias plantas medicinais diferentes juntas, acrescentando açúcar, mel, água e cozinhando até "dá o ponto".

As garrafadas são preparações constituídas de uma combinação de plantas medicinais, com uma finalidade específica, tendo como veículo água, aguardente ou vinho branco. Nelas as partes das plantas utilizadas, como a casca, entrecasca, folhas, frutos, contêm o necessário princípio ativo. Em botânica aplicada à farmácia essas partes constituem a droga. Assim nas garrafadas são reunidas as drogas cujos princípios ativos são indicados para um determinado mal (Camargo 1998).

Na Colônia Treze as garrafadas são preparadas e receitadas pelos praticantes da medicina popular, em particular os umbandistas. Foram encontradas várias receitas de garrafadas, utilizadas contra úlcera, inflamação, dores do corpo, derrame (acidente vascular cerebral) e resguardo quebrado, que Matos (2002) define como o conjunto de diversas afecções tidas como conseqüentes a sustos ou emoções fortes ou mesmo o não atendimento às normas populares que devem ser guardadas pelas parturientes durante 30 dias após o parto.

O suco das folhas das plantas foi outra forma de utilização encontrada. Geralmente são plantas com folhas mais grossas, como é o caso da couve branca (Brassica oleraceae L.). São trituradas em

Tabela 1. Plantas indicadas contra úlcera e gastrite na Colônia Treze e as selecionadas para os testes farmacológicos. (NR= Número de registro no herbário da UFS; ib = identificada com auxílio de bibliografia; SArb = subarbusto; Entrec = entrecasca; Arv = árvore; $\operatorname{Trp}=$ trepadeira Garr = garrafada; Sel = selecionada para os testes farmacológicos. Cat = Categoria do Informante: a - lideranças da comunidade; b - usuários; c - praticantes da medicina popular; - = planta não selecionada).

\begin{tabular}{|c|c|c|c|c|c|c|c|}
\hline Família/Espécie & Nome local & Cat & NR & Parte utilizada & Modo de uso & Hábito & Testes \\
\hline \multicolumn{8}{|l|}{ ANACARDIACEAE } \\
\hline $\begin{array}{l}\text { Schinus terebinthifolius Raddi. } \\
\text { BRASSICACEAE }\end{array}$ & aroeira-da-praia & $\mathrm{c}$ & $\mathrm{ib}$ & Entrec & Garr & Arv & - \\
\hline $\begin{array}{l}\text { Brassica oleraceae } \mathrm{L} . \\
\text { CAESALPINIACEAE }\end{array}$ & couve-branca & $\mathrm{b}, \mathrm{c}$ & $\mathrm{ib}$ & Folha & Suco & Erva. & Sel \\
\hline $\begin{array}{l}\text { Hymenaea } \text { sp. } \\
\text { CRASSULACEAE }\end{array}$ & jatobá & $\mathrm{c}$ & $\mathrm{ib}$ & Entrec & Garr & Arv & - \\
\hline Kalanchoe brasiliensis L. & folha-da-costa & $\mathrm{a}, \mathrm{b}, \mathrm{c}$ & 007623 & Folha & Sumo & Erva & Sel \\
\hline $\begin{array}{l}\text { Kalanchoe pinnata (Lam.) Pers. } \\
\text { ASTERACEAE }\end{array}$ & folha-da-costa & $\mathrm{b}$ & 007622 & Folha & Sumo & Erva & - \\
\hline $\begin{array}{l}\text { Baccharis sp. } \\
\text { CUCURBITACEAE }\end{array}$ & carqueja & $\mathrm{c}$ & ib & Folha & Sumo & Arb & - \\
\hline $\begin{array}{l}\text { Luffa cylindrica L. Roem } \\
\text { POACEAE }\end{array}$ & maxixão & $\mathrm{b}, \mathrm{c}$ & 007625 & Fruto verde & Chá & Erva & Sel \\
\hline $\begin{array}{l}\text { Cymbopogon citratus Stapf. } \\
\text { LAMIACEAE }\end{array}$ & capim-santo & $a, b$ & $\mathrm{ib}$ & Folha & Chá & Erva & - \\
\hline $\begin{array}{l}\text { Hyptis pectinata (L.) Poit. } \\
\text { LILIACEAE }\end{array}$ & canudinho & $\mathrm{b}, \mathrm{c}$ & $\mathrm{ib}$ & Toda a planta & Chá & SArb & - \\
\hline $\begin{array}{l}\text { Aloe sp. } \\
\text { MIMOSACEAE }\end{array}$ & babosa & $\mathrm{b}, \mathrm{c}$ & $\mathrm{ib}$ & Folha & Garr & Erva & - \\
\hline $\begin{array}{l}\text { Abarema cochliocarpos (Gomes) } \\
\text { Barneby \& Grimes }\end{array}$ & babatenã & $\mathrm{c}$ & 007628 & Casca & Chá & Arv & Sel \\
\hline $\begin{array}{l}\text { Mimosa verrucosa Benth. } \\
\text { EUPHORBIACEAE }\end{array}$ & jurema-lisa & $\mathrm{c}$ & $\mathrm{ib}$ & Entrec & Sumo & Arb & - \\
\hline $\begin{array}{l}\text { Manihot esculenta Crantz. } \\
\text { SOLANACEAE }\end{array}$ & mandioca & $\mathrm{c}$ & $\mathrm{ib}$ & Raiz & Sumo & Sumo & - \\
\hline Solanum tuberosum L. & batata inglesa & $\mathrm{c}$ & $\mathrm{ib}$ & Caule & Suco & SArb & - \\
\hline
\end{tabular}


liquidificador juntamente com água ou leite ou pisadas num pilão. De outras plantas tomam o sumo puro, como a carqueja (Bacharis trimera (Less.) DC.).

Defumador e banho também foram citados para "banhar ferida e para mulher parida", como o de canudinho (Hyptis pectinata (L.) Poit.) e babatenã (Abarema cochliocarpos (Gomes Barneby \& Grimes). Os banhos são também utilizados contra mauolhado e para abrir caminhos.

Os umbandistas foram os informantes que demonstraram ser os principais detentores do conhecimento tradicional sobre as plantas medicinais na comunidade. Foi essa categoria quem indicou as plantas contra úlcera. Já as plantas utilizadas contra distúrbios de motilidade foram indicadas pelas três categorias de informantes. Talvez por se tratar de plantas utilizadas para tratamentos de saúde mais corriqueiros, o conhecimento de seu uso esteja mais disseminado na comunidade.

Experimentos farmacológicos - Plantas Testadas no Modelo de Indução de Lesão Gástrica Aguda. Mourão et al. (1999) investigaram a toxicidade aguda de $K$. brasiliensis por via intraperitoneal e observaram que até a dose de $5 \mathrm{~g} \mathrm{~kg}^{-1}$ não houve registro de morte de animais. Estes dados indicam a baixa toxicidade dessa planta. O Extrato aquoso bruto (EAB) das folhas de Kalanchoe brasiliensis, nas doses de 100, 200 e $400 \mathrm{mg} \mathrm{kg}^{-1}$ mostrou-se eficiente na inibição de lesões ulcerativas induzidas por álcool, em relação ao controle. Os efeitos protetores do EA, administrado via oral, são mostrados na Tab. 3 e na Fig. 1. De acordo com estes dados, o EA apresentou atividade protetora não dosedependente. A droga de referência, ranitidina, também inibiu as lesões induzidas pelo álcool, porém esta inibição não foi completa na dose utilizada. A falha de antagonistas $\mathrm{H}_{2}$ em inibir completamente a lesão induzida pelo álcool também foi observada por outros pesquisadores (Robert et al. 1979). O mecanismo de ação antiulcerogênico da planta $K$. brasiliensis pode estar relacionado à inibição da atividade secretora de ácido gástrico, como faz a ranitidina, ou a um processo de citoporoteção. Não sabemos que constituintes químicos são responsáveis pela atividade antiulcerogênica desta espécie. Mourão et al. (1999) cita que a constituição química do suco da folhas de Kalanchoe é composta de flavonóides, ácido ascórbico e outros compostos. Pesquisas apontam que os flavonóides são substâncias capazes de capturar radicais livres, reconhecidos como um dos fatores lesivos da mucosa gástrica na lesão por álcool. Dessa forma, é possível

Tabela 2. Plantas indicadas contra distúrbios de motilidade, citados como dor de barriga, diarréia, inquitação, prisão de ventre e as selecionadas para os testes farmacológicos. ( $\mathrm{NR}=$ Número de registro no Herbário da UFS; ib = identificada com auxílio de bibliografia; $\mathrm{Arb}=$ arbusto; Arv = árvore; Ver = erva; Est = estipe; SArb = subarbusto;Trp = trepadeira; Testes = testes farmacológicos; Sel = selecionada; Cat. = Categoria do Informante: a - lideranças da comunidade; b - usuários; c - praticantes da medicina popular; - = planta não selecionada).

\begin{tabular}{|c|c|c|c|c|c|c|c|}
\hline Família/Espécie & Nome local & Cat & NR & Parte utilizada & Modo de uso & Hábito & Testes \\
\hline \multicolumn{8}{|l|}{ ALLIACEAE } \\
\hline $\begin{array}{l}\text { Allium sativum } \mathrm{L} . \\
\text { AMARANTHACEAE }\end{array}$ & alho & $\mathrm{c}$ & $\mathrm{ib}$ & Caule & Chá & Erva & - \\
\hline $\begin{array}{l}\text { Alternanthera brasiliana } \mathrm{L} \text {. } \\
\text { ANACARDIACEAE }\end{array}$ & farmacetina & $\mathrm{a}, \mathrm{b}$ & 007626 & Folhas & Chá & Erva & Sel \\
\hline $\begin{array}{l}\text { Spondias tuberosa Arr. Cam. } \\
\text { ARECACEAE }\end{array}$ & umbu & $\mathrm{b}$ & $i b$ & Folha & Chá & Arv & - \\
\hline $\begin{array}{l}\text { Cocus nucifera } \mathrm{L} \text {. } \\
\text { CARICACEAE }\end{array}$ & coco & $\mathrm{b}$ & $i b$ & Fibra & Chá & Est & Sel \\
\hline $\begin{array}{l}\text { Carica papaya } \mathrm{L} . \\
\text { ASTERACEAE }\end{array}$ & mamão & $\mathrm{b}, \mathrm{c}$ & $i b$ & Folha & Chá & Arv & - \\
\hline $\begin{array}{l}\text { Egletes viscosa }(\mathrm{L} .) \text { Less. } \\
\text { Vernonia condensata Baker }\end{array}$ & $\begin{array}{l}\text { macela } \\
\text { alumã }\end{array}$ & $\begin{array}{c}\mathrm{v} \\
\mathrm{a}, \mathrm{b}, \mathrm{c}\end{array}$ & $\begin{array}{c}\text { ib } \\
007624\end{array}$ & $\begin{array}{l}\text { Folha } \\
\text { Folha }\end{array}$ & $\begin{array}{l}\text { Chá } \\
\text { Chá }\end{array}$ & $\begin{array}{l}\text { Erva } \\
\text { Arb }\end{array}$ & $\begin{array}{c}- \\
\text { Sel }\end{array}$ \\
\hline LAMIACEAE & & & & & & & \\
\hline $\begin{array}{l}\text { Ocimum gratissimum } \mathrm{L} . \\
\text { MYRTACEAE }\end{array}$ & tioiô & $\mathrm{a}, \mathrm{b}, \mathrm{c}$ & 007627 & Folha & Chá & SArb & Sel \\
\hline $\begin{array}{l}\text { Psidium guajava L. } \\
\text { RUTACEAE }\end{array}$ & goiabeira & $\mathrm{b}, \mathrm{c}$ & $\mathrm{ib}$ & Broto & Chá & Arv & - \\
\hline $\begin{array}{l}\text { Ruta graveolens } \mathrm{L} . \\
\text { VERBENACEAE }\end{array}$ & arruda & $\mathrm{b}, \mathrm{c}$ & $\mathrm{ib}$ & Folha & Chá & SArb & - \\
\hline Lippia sp. & erva-cidreira & $a, b, c$ & $i b$ & Folha & Chá & Erva & - \\
\hline
\end{tabular}


Tabela 3. Atividade antiulcerogênica do extraro aquoso das folhas de Kalanchoe brasiliensis L. na lesão gástrica induzida por álcool em ratos. (v.o. = via oral; $\mathrm{UI}=$ índice de úlcera; $\mathrm{EA}=$ extrato aquoso).

\begin{tabular}{lccc}
\hline $\begin{array}{l}\text { Tratamentos } \\
(\text { v.o })\end{array}$ & $\begin{array}{c}\text { UI } \\
(\mathrm{mm})\end{array}$ & $\begin{array}{c}\text { Número } \\
\text { estômagos } / \mathrm{n}\end{array}$ & $\begin{array}{c}\text { Inibição da } \\
\text { úlcera }(\%)\end{array}$ \\
\hline Controle & $51,1 \pm 6,5$ & $0 / 9$ & - \\
Ranitidina $\left(50 \mathrm{mg} \mathrm{kg}^{-1}\right)$ & $18,8 \pm 5,0^{*}$ & $0 / 9$ & 63,20 \\
EA 100 mg kg-1 & $21,38 \pm 5,2^{*}$ & $0 / 9$ & 57,70 \\
EA 200 mg kg-1 & $16,57 \pm 4,2^{*}$ & $1 / 7$ & 67,57 \\
EA 400 mg kg & $18,14 \pm 7,6^{*}$ & $0 / 9$ & 64,50 \\
\hline
\end{tabular}

a - número de estômagos que apresentaram inibição total de hemorragias ou lesões. Os resultados são expressos como média \pm erro padrão. ANOVA: $F(4,36)=2.69$, seguido do Teste de Dunnett: $* \mathrm{p}<0.001$, versus controle.

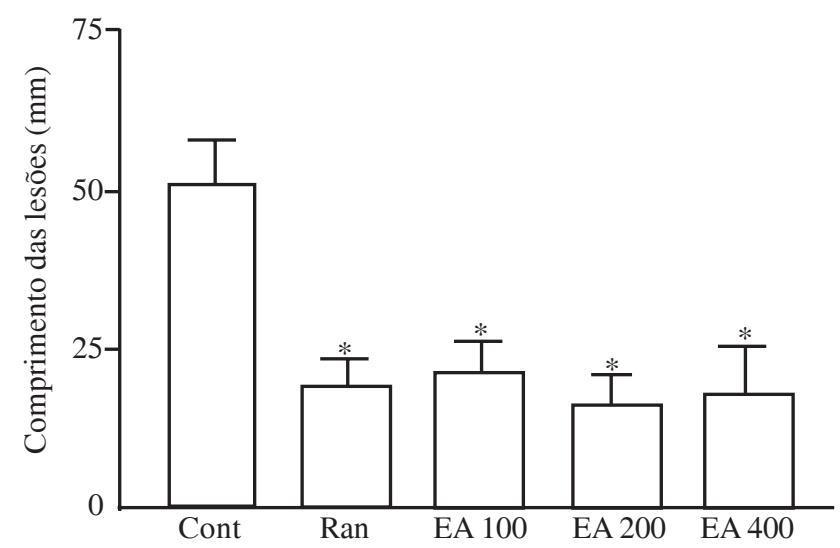

Figura 1. Efeito da ranitidina e das diferentes doses do extrato aquoso de Kalanchoe brasiliensis L. em relação ao comprimento das lesões gástricas induzidas por álcool. (Cont = controle; $\mathrm{Ran}=$ ranitidina; EA100 = extrato aquoso $100 \mathrm{mg} \mathrm{kg}^{-1}$, via oral; EA200 = extrato aquoso $200 \mathrm{mg} \mathrm{kg}^{-1}$, via oral; EA400 = extrato aquoso $400 \mathrm{mg} \mathrm{kg}^{-1}$, via oral; *p $<0.001$, versus controle).

que a atividade inibitória da lesão gástrica de $K$. brasiliensis seja devido aos flavonóides como um mecanismo de citoproteção.

A. cochliocarpos é uma árvore com frutos contorcidos, sementes brancas e cinzas. Flores com estames alvos. Tem distribuição na Mata Atlântica, entre manchas de cerrado em contato com a caatinga. Está incluída entre as espécies ameaçadas de extinção, classificada como vulnerável. (Internacional Union For Conservation 2006). Não há relatos na literatura sobre a atividade farmacológica desta planta, indicando que é ainda uma espécie pouco conhecida da comunidade acadêmica. O EA da casca de A. cochliocarpos nas doses de 100, 200 e $400 \mathrm{mg} \mathrm{kg}^{-1}$ mostrou uma significante redução das lesões gástricas produzidas pelo álcool, quando comparado com o controle Tab. 4 e na Fig. 2. Estes dados mostram que o EA da casca de A. cochliocarpos apresentou atividade protetora dose-dependente, sendo capaz de inibir quase completamente as lesões na dose de $400 \mathrm{mg} \mathrm{kg}^{-1}$ (99.04\%). Quando comparado com a ação da Ranitidina na dose de $50 \mathrm{mg} \mathrm{kg}^{-1}$, o EA mostrou uma inibição mais significativa das lesões induzidas pelo álcool $(\mathrm{p}<0.001)$. Estes resultados sugerem que o mecanismo de ação antiulcerogênico da planta pode estar relacionado tanto a inibição da secreção ácida gástrica quanto a outros mecanismos de proteção da mucosa gástrica.

O EA do fruto verde de Luffa cylindrica mostrou significante atividade antiulcerogênica na dose de $400 \mathrm{mg} \mathrm{kg}^{-1}$ como mostrado na Tab. 5 e na Fig. 3. Na dose de $400 \mathrm{mg} \mathrm{kg}^{-1}$, o EA mostrou-se mais eficiente do que a Ranitidina, na dose utilizada na inibição da secreção ácida gástrica. Estes resultados sugerem que

Tabela 4. Atividade antiulcerogênica do extrato aquoso da casca de Abarema cochliocarpos (Gomes) Barneby \& Grimes na lesão gástrica induzida por álcool em ratos. (v.o. = via oral; UI = índice de úlcera; EA = extrato aquoso).

\begin{tabular}{lccc}
\hline $\begin{array}{l}\text { Tratamentos } \\
(\text { v.o })\end{array}$ & $\begin{array}{c}\text { UI } \\
(\mathrm{mm})\end{array}$ & $\begin{array}{c}\text { Número } \\
\text { estômagos } / \mathrm{n}\end{array}$ & $\begin{array}{c}\text { Inibição da } \\
(\%)\end{array}$ \\
\hline Controle & $35,55 \pm 6,6$ & $0 / 11$ & - \\
Ranitidina $\left(50 \mathrm{mg} \mathrm{kg}^{-1}\right)$ & $18,80 \pm 5,01 * *$ & $0 / 9$ & 47,11 \\
EA 100 mg kg-1 & $6,71 \pm 1,75 *$ & $1 / 9$ & 81,11 \\
EA 200 mg kg-1 & $1,97 \pm 0,93 *$ & $2 / 9$ & 94,45 \\
EA 400 mg kg-1 & $0,34 \pm 0,17 *$ & $5 / 9$ & 99,04 \\
\hline
\end{tabular}

a - número de estômagos que apresentaram inibição total de hemorragias ou lesões. Os resultados são expressos como média \pm erro padrão. ANOVA: $\mathrm{F}(4,42)=2,61$, seguido do Teste de Dunnett: $* \mathrm{p}<0,001$, versus controle, ${ }^{* *} \mathrm{p}<0.05$, versus controle.

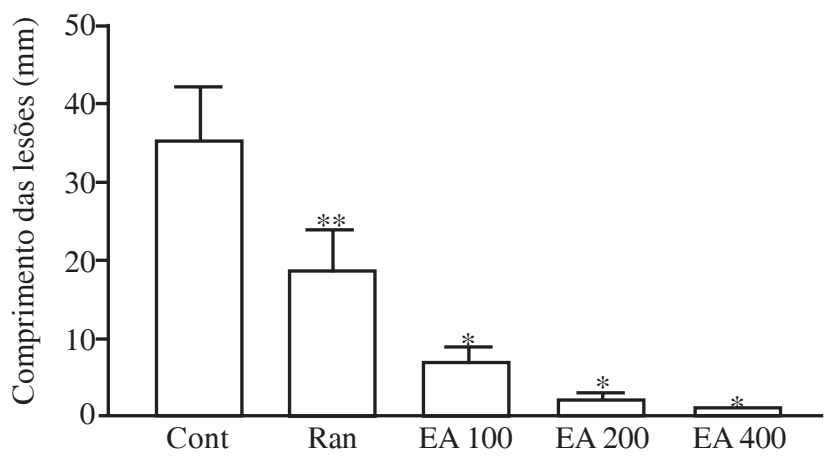

Figura 2. Efeito da ranitidina e das diferentes doses do extrato aquoso de Abarema cochliocarpos (Gomes) Barneby \& Grimes nas lesões gástricas induzidas por álcool. (Cont = controle; Ran = Ranitidina; EA100 = extrato aquoso $100 \mathrm{mg} \mathrm{kg}^{-1}$, via oral; EA200 = extrato aquoso $200 \mathrm{mg} \mathrm{kg}^{-1}$, via oral; EA400 = extrato aquoso $400 \mathrm{mg} \mathrm{kg}^{-1}$, via oral; *p $<0,001$, versus controle; $* * \mathrm{p}<0.05$, versus controle). 
o mecanismo de ação do EA de L. cylindrica pode estar relacionado à inibição da secreção ácida gástrica e a outros mecanismos. O fruto de L. cylindrica contém glicosídeos saponínicos (Schvartsman 1979). As saponinas têm sido implicadas como agentes antiulcerogênicos cuja ação é mediada pela formação de um muco protetor na mucosa gástrica (Guaraldo 2001). É possível que estes constituintes estejam relacionados a um mecanismo citoprotetor da mucosa.

$\mathrm{O}$ EA das folhas de $B$. oleraceae nas doses de 200 e $400 \mathrm{mg} \mathrm{kg}^{-1}$ mostrou significante atividade antiulcerogênica mostrada na Tab. 6 e na Fig. 4. Estes resultados mostram que o efeito inibitório do EA de B. oleraceae não foi dose-dependente, quando comparado com o controle. A efetividade do EA em impedir as lesões gástricas foi equivalente a da Ranitidina, o que sugere um mecanismo de ação

Tabela 5. Atividade antiulcerogênica do extrato aquoso de Luffa cylindrica L. Roem na indução de lesão gástrica por álcool em ratos. (v.o. = via oral; UI = índice de úlcera; $\mathrm{EA}=$ extrato aquoso).

\begin{tabular}{lllc}
\hline $\begin{array}{l}\text { Tratamentos } \\
(\text { v.o })\end{array}$ & \multicolumn{1}{c}{$\begin{array}{c}\text { UI } \\
(\mathrm{mm})\end{array}$} & $\begin{array}{c}\text { Número } \\
\text { estômagos } / \mathrm{n}\end{array}$ & $\begin{array}{c}\text { Inibição da } \\
(\%)\end{array}$ \\
\hline Controle & $56,72 \pm 13,67$ & $0 / 9$ & - \\
Ranitidina $\left(50 \mathrm{mg} \mathrm{kg}^{-1}\right)$ & $18,80 \pm 5,011^{*}$ & $0 / 9$ & 66,85 \\
EA 100 mg kg-1 & $45,08 \pm 9,93$ & $0 / 8$ & 20,52 \\
EA 200 mg kg-1 & $31,42 \pm 7,081$ & $0 / 9$ & 44,60 \\
EA 400 mg kg-1 & $3,571 \pm 1,25^{* *}$ & $2 / 7$ & 93,70 \\
\hline
\end{tabular}

a - número de estômagos que apresentaram inibição total de hemorragias ou lesões. Os resultados são expressos como média \pm erro padrão. ANOVA: $\mathrm{F}(4,37)=2.69$, seguido do Teste de Dunnett: $* \mathrm{p}<0.05$, versus controle, $* * \mathrm{p}<0.001$.

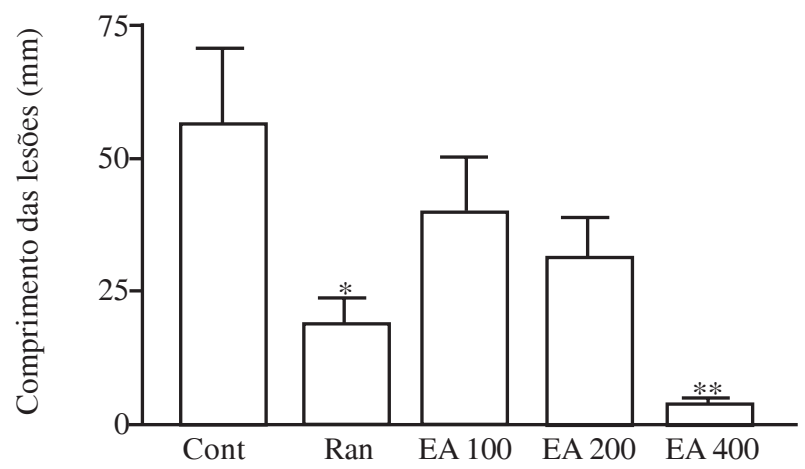

Figura 3. Efeito da ranitidina e das diferentes doses do extrato aquoso de Luffa cylindrica L. nas lesões gástricas induzidas por álcool. $($ Cont $=$ controle RAN $=$ Ranitidina; EA100 $=$ extrato aquoso $100 \mathrm{mg} \mathrm{kg}^{-1}$, via oral; EA200 = extrato aquoso $200 \mathrm{mg} \mathrm{kg}^{-1}$, via oral; EA400 = extrato aquoso $400 \mathrm{mg} \mathrm{kg}^{-1}$, via oral. ${ }^{*} \mathrm{p}<0.05$, versus controle, $* * \mathrm{p}<0.001)$.
Tabela 6. Atividade antiulcerogênica do extrato aquoso de Brassica oleraceae L. na indução de lesão gástrica por álcool em ratos. (v.o. = via oral; $\mathrm{UI}=$ índice de úlcera $; \mathrm{EA}=$ extrato aquoso).

\begin{tabular}{lllc}
\hline $\begin{array}{l}\text { Tratamentos } \\
(\text { v.o })\end{array}$ & \multicolumn{1}{c}{$\begin{array}{c}\text { UI } \\
(\mathrm{mm})\end{array}$} & $\begin{array}{c}\text { Número } \\
\text { estômagos } / \mathrm{n}\end{array}$ & $\begin{array}{c}\text { Inibição da } \\
(\%)\end{array}$ \\
\hline Controle & $62,44 \pm 9,6$ & $0 / 9$ & - \\
Ranitidina $\left(50 \mathrm{mg} \mathrm{kg}^{-1}\right)$ & $18,80 \pm 5,01 *$ & $0 / 9$ & 69,89 \\
EA 100 mg kg-1 & $39,83 \pm 11,39$ & $0 / 9$ & 36,21 \\
EA 200 mg kg-1 & $22,07 \pm 3,84 * *$ & $0 / 9$ & 64,65 \\
EA 400 mg kg & $31,11 \pm 7,19 * * *$ & $0 / 9$ & 50,17 \\
\hline
\end{tabular}

a - número de estômagos que apresentaram inibição total de hemorragias ou lesões. Os resultados são expressos como média \pm erro padrão. ANOVA: $F(4,40)=2.61$, seguido do Teste de Dunnett: ${ }^{*} \mathrm{p}<0.001$, versus controle, ${ }^{* *} \mathrm{p}<0.001$, versus controle, ${ }^{* * *} \mathrm{p}<0.05$, versus controle.

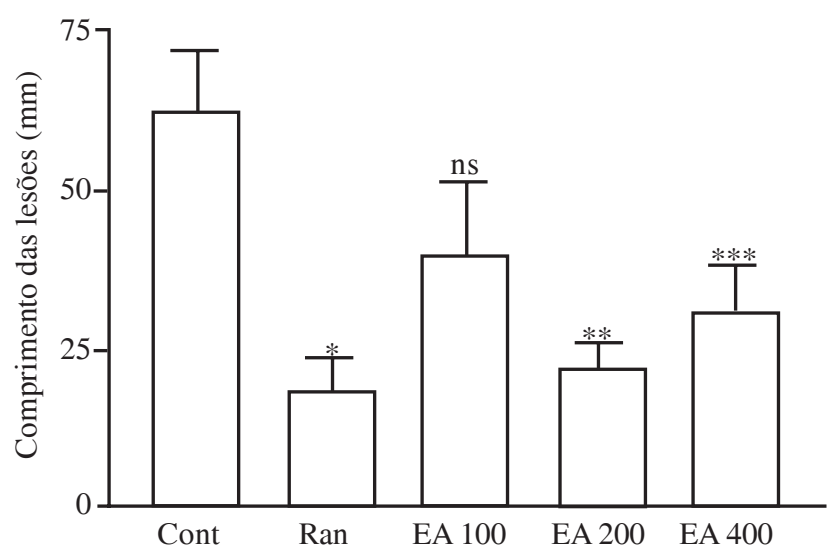

Figura 4. Efeito da ranitidina e das diferentes doses do extrato aquoso de Brassica oleraceae L. nas lesões gástricas induzidas por álcool. $($ Cont $=$ controle $;$ Ran $=$ Ranitidina $;$ EA $100=$ extrato aquoso $100 \mathrm{mg} \mathrm{kg}^{-1}$, via oral; EA200 = extrato aquoso $200 \mathrm{mg} \mathrm{kg}^{-1}$, via oral; EA400 $=$ extrato aquoso $400 \mathrm{mg} \mathrm{kg}^{-1}$, via oral. $* \mathrm{p}<0.001$, versus controle, $* * \mathrm{p}<0.001$, versus controle, $* * * \mathrm{p}<0.05$ versus controle.

do EA relacionado à inibição da secreção ácida gástrica.

Estudos feitos por Aktar e Munir (1989) com B. oleraceae var. botrytis L. para verificação de possível atividade antiulcerogênica do EA e do extrato metanólico desta espécie, submetida ao modelo de indução de lesão gástrica induzida por aspirina em ratos, mostraram que o EA desta variedade diminuiu o índice de úlcera, a liberação de ácido gástrico e de pepsina, e aumentou significativamente os níveis de hexosamina, um componente do muco. Investigações futuras são necessárias para isolar os princípios ativos de B. oleraceae, relacionados com seu(s) mecanismo(s) de atividade antiulcerogênica.

Plantas testadas no modelo de trânsito intestinal - O EA de $V$. condensata por via oral não induziu morte 
ou sinal de toxicidade até a dose de $5.000 \mathrm{mg} \mathrm{kg}^{-1}$. Estes resultados indicam que a planta tem baixa toxicidade aguda. Outros pesquisadores chegaram a resultados semelhantes quanto à toxicidade aguda oral da planta (Monteiro et al. 2001). No presente experimento, O EA de $V$. condensata nas doses testadas não alterou a propulsão intestinal (Tab. 7) . Outros estudos farmacológicos do EA das folhas de $V$. condensata e o isolamento de compostos de seu extrato metanólico revelaram propriedades analgésicas e antiinflamatórias dessa espécie (Valverde et al. 2001).

O EA de $O$. gratissimum por via oral não induziu morte ou sinal de toxicidade até a dose de $5.000 \mathrm{mg} \mathrm{kg}^{-1}$. Estes resultados indicam que a planta tem baixa toxicidade aguda. Nos experimentos de trânsito intestinal o EA de $O$. gratissimum nas doses de 100,200 e $400 \mathrm{mg} \mathrm{kg}^{-1}$ não alterou significativamente a motilidade intestinal quando comparado ao controle, como mostra os resultados na Tab. 8. A droga de referência utilizada, atropina, não produziu inibição completa da motilidade intestinal. Isso se deve à importância de transmissores excitatórios diferentes da acetilcolina na função normal do plexo mioentérico (Rang 2001) ou ao fato da dose utilizada não ter sido suficiente para produzir inibição completa.

O EA de A. brasiliana por via oral não induziu morte ou sinal de toxicidade até a dose de $5.000 \mathrm{mg} \mathrm{kg}^{-1}$. Estes resultados indicam que a planta tem baixa toxicidade aguda. O EA de A. brasiliana não foi eficiente na alteração da motilidade intestinal quando comparado com o controle, conforme Tab. 9.

O EA da fibra de $C$. nucifera não se mostrou eficiente na alteração da motilidade intestinal, quando comparado com o controle, conforme a Tab. 10.

Os resultados da avaliação farmacológica das plantas medicinais selecionadas para o estudo revelaram que, no modelo utilizado, nenhuma das plantas indicadas contra distúrbios de motilidade gastrintestinal mostrou-se eficiente. Porém, todas as plantas indicadas contra úlcera e gastrite mostraram-se

Tabela 7. Efeitos do extrato aquoso de Vernonia condensata Baker no trânsito intestinal em ratos. (v.o = via oral; EA= extrato aquoso).

\begin{tabular}{|c|c|c|c|}
\hline Tratamento (v.o) & $\begin{array}{l}\text { Média do comprimento } \\
\text { intestino }(\mathrm{cm})\end{array}$ & $\begin{array}{l}\text { Média da distância percorrida } \\
\text { pelo carvão }(\mathrm{cm})\end{array}$ & $\begin{array}{l}\text { \% Percorrida pelo } \\
\text { carvão }\end{array}$ \\
\hline Controle $(\mathrm{n}=14)$ & $93,65 \pm 1,57$ & $63,61 \pm 1,61$ & $68,0 \pm 1,64$ \\
\hline $\begin{array}{l}\text { Atropina }(\mathrm{n}=7) \\
\quad\left(2 \mathrm{mg} \mathrm{kg}^{-1}\right)\end{array}$ & $87,17 \pm 2,29$ & $50,14 \pm 3,91 *$ & $57,37 \pm 3,87$ \\
\hline $\begin{array}{l}\mathrm{EA}(\mathrm{n}=7) \\
\quad\left(100 \mathrm{mg} \mathrm{kg}^{-1}\right)\end{array}$ & $79,53 \pm 3,74$ & $56,31 \pm 3,06$ & $67,39 \pm 2,41$ \\
\hline $\begin{array}{l}\text { EA }(\mathrm{n}=7) \\
\quad\left(200 \mathrm{mg} \mathrm{kg}^{-1}\right)\end{array}$ & $83,74 \pm 1,86$ & $60,79 \pm 2,14$ & $72,56 \pm 20,2$ \\
\hline $\begin{array}{l}\text { EA }(\mathrm{n}=7) \\
\quad\left(400 \mathrm{mg} \mathrm{kg}^{-1}\right)\end{array}$ & $91,30 \pm 2,82$ & $64,30 \pm 4,24$ & $70,19 \pm 3,67$ \\
\hline
\end{tabular}

Os resultados são expressos como média \pm erro padrão. ANOVA: $\mathrm{F}(4,37)=2.69$, seguido do Teste de Dunnett: *p < 0.05 , versus controle.

Tabela 8. Efeitos do extrato aquoso de Ocimum gratissimum L. no trânsito intestinal em ratos. (v.o. = via oral; EA = extrato aquoso).

\begin{tabular}{|c|c|c|c|}
\hline Tratamento (v.o) & $\begin{array}{l}\text { Média do comprimento } \\
\text { intestino }(\mathrm{cm})\end{array}$ & $\begin{array}{l}\text { Média da distância percorrida } \\
\text { pelo carvão }(\mathrm{cm})\end{array}$ & $\begin{array}{l}\% \text { Percorrida pelo } \\
\text { carvão }\end{array}$ \\
\hline Controle $(n=14)$ & $93,65 \pm 1,57$ & $63,61 \pm 1,61$ & $68,01 \pm 1,64$ \\
\hline $\begin{array}{l}\text { Atropina }(\mathrm{n}=7) \\
\quad\left(2 \mathrm{mg} \mathrm{kg}^{-1}\right)\end{array}$ & $87,17 \pm 2,29$ & $50,14 \pm 3,91^{*}$ & $57,37 \pm 3,87$ \\
\hline $\begin{array}{l}\mathrm{EA}(\mathrm{n}=7) \\
\quad\left(100 \mathrm{mg} \mathrm{kg}^{-1}\right)\end{array}$ & $87,36 \pm 3,03$ & $66,30 \pm 3,50$ & $72,59 \pm 4,05$ \\
\hline $\begin{array}{l}\text { EA }(\mathrm{n}=7) \\
\quad\left(200 \mathrm{mg} \mathrm{kg}^{-1}\right)\end{array}$ & $91,44 \pm 5,10$ & $62,81 \pm 3,84$ & $68,59 \pm 1,43$ \\
\hline $\begin{array}{l}\text { EA }(\mathrm{n}=7) \\
\quad\left(400 \mathrm{mg} \mathrm{kg}^{-1}\right)\end{array}$ & $89,29 \pm 2,84$ & $62,17 \pm 2,28$ & $69,60 \pm 1,34$ \\
\hline
\end{tabular}

Os resultados são expressos como média \pm erro padrão. ANOVA: $\mathrm{F}(4,37)=2.69$, seguido do Teste de Dunnett: *p $<0.001$, versus controle. 
com ação antiulcerogênica. Reconhece-se, dessa forma, o valor do conhecimento tradicional como subsídio para a geração do conhecimento científico, neste caso abrindo caminhos para o desenvolvimento de novos estudos sobre essas plantas, visando evidenciar sua propriedade terapêutica, podendo levar à produção de fármacos mais eficazes contra esses distúrbios e a preços mais acessíveis.

A análise do uso popular das plantas medicinais no Povoado Colônia Treze revela-nos um quadro de enorme riqueza cultural associado às precárias condições econômicas vividas pela maior parte de sua população. As plantas medicinais surgem como instrumento de cura, cujo uso é gerado e sustentado pela cultura local.

Para os usuários da medicina popular do Povoado, as plantas são quase sempre o recurso primário de atenção à saúde, seja pela falta de condições de adquirirem medicamentos alopáticos, ou pelo difícil acesso ao sistema de saúde oficial. Apesar da existência nessa comunidade de Postos de Saúde com boa estrutura física, atualmente existe carência de profissionais. O médico do Programa de Saúde da Família atende nesses postos, mas é dedicado apenas um dia da semana para cada localidade do Povoado, não suprindo, portanto, as necessidades da população. Dessa forma, a medicina popular assume papel fundamental no atendimento à saúde dessa comunidade, sendo praticada por pessoas que vivem na comunidade e conhecem seus pacientes.

A riqueza em flora medicinal, ainda apresentada pela região Nordestina, é tão grande quanto o conhecimento popular a ela associado. As pessoas que conhecem essas plantas colaboram para seu cultivo e preservação, selecionando as plantas de seu interesse, mantendo-se sua diversidade biológica.

Estudos etnobotânicos indicam que as pessoas afetam a estrutura das comunidades vegetais e paisagens, a evolução de espécies individuais, a biologia de determinadas populações de plantas de interesse

Tabela 9. Efeitos do EA de Alternanthera brasiliana L. no trânsito intestinal em ratos. (v.o. = via oral; EA = extrato aquoso).

\begin{tabular}{|c|c|c|c|}
\hline Tratamento (v.o) & $\begin{array}{l}\text { Média do comprimento } \\
\text { intestino }(\mathrm{cm})\end{array}$ & $\begin{array}{l}\text { Média da distância percorrida } \\
\text { pelo carvão }(\mathrm{cm})\end{array}$ & $\begin{array}{c}\text { \% Percorrida pelo } \\
\text { carvão }\end{array}$ \\
\hline Controle $(\mathrm{n}=14)$ & $93,65 \pm 1,57$ & $63,61 \pm 1,61$ & $68,01 \pm 1,64$ \\
\hline $\begin{array}{l}\text { Atropina }(\mathrm{n}=7) \\
\quad\left(2 \mathrm{mg} \mathrm{kg}^{-1}\right)\end{array}$ & $87,17 \pm 2,29$ & $50,14 \pm 3,91 *$ & $57,37 \pm 3,87$ \\
\hline $\begin{array}{l}\text { EA }(n=9) \\
\quad\left(100 \mathrm{mg} \mathrm{kg}^{-1}\right)\end{array}$ & $96,48 \pm 1,44$ & $62,18 \pm 5,04$ & $64,30 \pm 4,73$ \\
\hline $\begin{array}{l}\text { EA }(\mathrm{n}=9) \\
\quad\left(200 \mathrm{mg} \mathrm{kg}^{-1}\right)\end{array}$ & $96,20 \pm 1,51$ & $57,82 \pm 2,91$ & $60,26 \pm 3,17$ \\
\hline $\begin{array}{l}\text { EA }(\mathrm{n}=9) \\
\quad\left(400 \mathrm{mg} \mathrm{kg}^{-1}\right)\end{array}$ & $100 \pm 1,56$ & $61,17 \pm 2,16$ & $61,26 \pm 2,30$ \\
\hline
\end{tabular}

Os resultados são expressos como média \pm erro padrão. ANOVA: $\mathrm{F}(4,43)=2.61$, seguido do Teste de Dunnett: *p $<0.05$, versus controle

Tabela 10. Efeitos do EA de Coccus nucifera L. no trânsito intestinal em ratos. (v.o. = via oral; EA= extrato aquoso).

\begin{tabular}{|c|c|c|c|}
\hline Tratamento (v.o) & $\begin{array}{l}\text { Média do comprimento } \\
\text { intestino }(\mathrm{cm})\end{array}$ & $\begin{array}{c}\text { Média da distância percorrida } \\
\text { pelo carvão }(\mathrm{cm})\end{array}$ & $\begin{array}{l}\% \text { Percorrida pelo } \\
\text { carvão }\end{array}$ \\
\hline Controle $(n=14)$ & $93,65 \pm 1,57$ & $63,61 \pm 1,61$ & $68,01 \pm 1,64$ \\
\hline $\begin{array}{l}\text { Atropina }(\mathrm{n}=7) \\
\quad\left(2 \mathrm{mg} \mathrm{kg}^{-1}\right)\end{array}$ & $87,17 \pm 2,29$ & $50,14 \pm 3,91 *$ & $57,37 \pm 3,87$ \\
\hline $\begin{array}{l}\text { EA }(n=9) \\
\quad\left(100 \mathrm{mg} \mathrm{kg}^{-1}\right)\end{array}$ & $91,59 \pm 1,76$ & $63,11 \pm 2,01$ & $69,52 \pm 1,97$ \\
\hline $\begin{array}{l}\text { EA }(n=7) \\
\quad\left(200 \mathrm{mg} \mathrm{kg}^{-1}\right)\end{array}$ & $95,16 \pm 3,36$ & $68,01 \pm 3,42$ & $71,33 \pm 1,92$ \\
\hline $\begin{array}{l}\text { EA }(n=7) \\
\quad\left(400 \mathrm{mg} \mathrm{kg}^{-1}\right)\end{array}$ & $92,60 \pm 3,05$ & $67,66 \pm 2,89$ & $74,85 \pm 2,63$ \\
\hline
\end{tabular}

Os resultados são expressos como média \pm erro padrão. ANOVA: $\mathrm{F}(4,39)=2.69$, seguido do Teste de Dunnett: *p $<0.001$, versus controle. 
não apenas sob aspectos negativos, como comumente se credita à intervenção humana, mas beneficiando e promovendo os recursos manejados (Albuquerque \& Andrade 2002).

É fundamental que o conhecimento popular gerado nessa comunidade possa ser compartilhado com as gerações mais jovens, tornando-se necessárias estratégias de desenvolvimento para essas comunidades que despertem o interesse dessas gerações, como a criação de espaços, como os hortos medicinais ou Farmácias Vivas, onde esse conhecimento possa ser mantido e fortalecido através de mecanismos de geração de renda e de valorização desse conhecimento. Podendo assim haver o retorno dos benefícios advindos do conhecimento empírico generosamente fornecido por essas comunidades em forma de melhoria de sua qualidade de vida.

\section{Agradecimentos}

Agradecemos aos moradores do Povoado Colônia Treze, especialmente aos informantes que participaram desta pesquisa, pela atenção dispensada; à Universidade Federal de Sergipe, por possibilitar a realização da pesquisa; ao Centro Federal de Educação Tecnológica de Sergipe e à Fundação Universidade Estadual de Alagoas, pela concessão de licença para estudos para a primeira autora.

\section{Referências bibliográficas}

Amoroso, M.C.M. 2002. Agricultura Tradicional, Espaços de Resistência e o Prazer de Plantar. Pp. 123-131. In: U.P. Albuquerque; A.G. Chavez Alves; A.C. Borges Lins e Silva \& V.A. Silva (orgs.). Atualidades em Etnobiologia e Etnoecologia. Recife, SBEE.

Albuquerque, U.P. 2005. Introdução à Etnobotânica. Rio de Janeiro, Editora Interciência.

Albuquerque, U.P. \& Andrade L.H.C. 2002. Conhecimento Botânico Tradicional e Conservação em uma Área de Caatinga no Estado de Pernambuco, Nordeste do Brasil. Acta Botanica Brasilica 16(3): 273-285.

Aktar, M.S. \& Munir, M. 1989. Evaluation of the gastric antiulcerogenic effects of Solanum nigrum, Brassica oleraceae and Ocimum basilicum in rats. Journal of Ethnopharmacology 27:163-176.

Brasil, 1995. ITTO/IBAMA/FUNATURA. Diagnóstico Florestal de Sergipe. Brasília, Aracaju, Recife, ITTO/ IBAMA/FUNATURA

Brasil, 2000. Instituto Brasileiro de Geografia e Estatística. Censo Demográfico. Rio de Janeiro, IBGE.

Brasil, 2001. Ministério do Meio Ambiente. Saberes Tradicionais e Biodiversidade no Brasil. Brasília, MMA/ NUPAUB-USP
Brasil, 2002. Instituto Brasileiro de Geografia e Estatística. Indicadores de Desenvolvimento Sustentável. Rio de Janeiro (Estudos e pesquisas geográficas 2), IBGE

Camargo, M.T.L.A. 1998. Plantas Medicinais e de Rituais Afro-brasileiros II: estudo etnofarmacobotânico. São Paulo, Ícone.

Carrara, D. 1995. Possangaba: o pensamento médico popular. Maricá, RJ, Ribro Soft.

Deslandes, S.F. 1997. Concepções em pesquisa social: articulações com o campo da avaliação em serviço de saúde. Cadernos de Saúde Pública 13(1): 103-107.

Elisabetsky, E. 2001. Etnofarmacologia como Ferramenta na Busca de Substâncias Ativas. Pp. 91-103. In: C.M.O. Simões; E.P. Schenkel; G. Gosman; J.C.P. Mello; L.A. Mentz \& P.R. Petrovick (orgs.). Farmacognosia: da Planta ao Medicamento. 3 ed. rev. Porto Alegre, EdUFRGS; Florianópolis, EdUFSC.

Elizabetsky, E. 2003. Etnofarmacologia. Ciência e Cultura 55(3): 35-36.

Hiruma-Lima, C.A.; Gracioso, J.S.; Rodriguez, J.A.; Haun, M.; Nunes, D.S. \& Souza-Brito, A.R.M. 2000. Gastroprotective Effect of Essential Oil from Croton cajucara Benth. (Euphorbiaceae) Journal of Ethnopharmacology 69(3): 229-234.

Lagarto, 2002. Secretaria Municipal de Saúde. SIAB-Sistema de Informação de Atenção Básica.

Lévêque, Christian,1999. A Biodiversidade. Trad. Valdo Mermelstein. Bauru, EDUSC.

Lisboa, J.B. 2001. Associativismo no campo: das relações em redes ao espaço da socialização política. Dissertação (Mestrado em Geografia). In: A.V.C. Menezes; J.E.S.S. Pinto (org.). Linhas geográficas. Aracaju, NPGEO/UFS. Série dissertações.

Matos, F.J. A. 2002. Farmácias vivas. 4. ed. rev. Fortaleza, UFC/SEBRAE.

Minayo, M.C.S. 1991. Abordagem antropológica para avaliação de políticas sociais. Revista de Saúde Pública 25(3): 233-238.

Mourão, R.H.V.; Santos, F.O.; Franzotti, E.M.; Moreno, M.P.N. \& Antoniolli, A.R. 1999. Antiinflammatory activity and acute toxicity $\left(\mathrm{LD}_{50}\right)$ of the juice of Kalanchoe brasiliensis (Comb.) leaves picked before and during blooming. Phytotherapy Research 13: 352-354.

Rang, H.P.; Dale, M.M. \& Ritter, J.M. 2001.Farmacologia. 4. ed. Rio de Janeiro, Guanabara Koogan.

Schvartsman, S. 1979. Plantas venenosas. São Paulo, Sarvier. Internacional Union for Conservation of Nature and Natural Resources-Iucn. Red list of threatened species, 2006. Disponível em: www.redlist.org (Acesso: 22/06/2006).

Guaraldo, L.; Sertiè, J.A.A. \& Bacchi, E.M. 2001.Antiulcer action of the hydroalcoholic extract and fractions of Davilla rugosa Poiret in the rat. Journal of Ethnopharmacology 76: 191-195.

Monteiro, M.H.D.; Gomes-Carneiro, M.R.; Felzenszwalb, I.; Chahoud, I. \& Paumgartten, F.J.R. 2001.Toxicological evaluation of a tea from leaves of Vernonia condensata. Journal of Ethnopharmacology 74: 149-157. 
Robert, A.; Nezamis, J.E.; Lancaster, C. \& Hanchar, A.J. 1979. Cytoprotection by prostaglandins in rats: prevencion of gastric necrosis produced by alcohol, $\mathrm{HCl}, \mathrm{NaOH}$, hypertonic $\mathrm{NaCl}$, and thermal injury. Gastroenterology, 77: 433-443.

Valverde, A.L.; Cardoso, G.L.C.; Pereira, N.A.; Silva, A.J.R.; \& Kuster, R.M. 2001. Analgesic and antiinflamatory activities of vernonioside B2 from Vernonia condensata. Phytotherapy Research 15: 263-264.

Rao, V.S.N.; Santos, F.A.; Sobreira, T.T.; Souza, M.F.; Melo, C.L. \& Silveira, E.R. 1997. Investigations on the gastroprotective and antidiarrhoeal properties of ternatin, a tetramethoxyflavone from Egletes viscosa. Planta Medica 63: 146-149.

Singh, S. \& Majundar, D.K. 1999. Evaluation of gastric antiulcerative activity of fixed oil Ocimun sanctum (Holy Basil). Journal of Ethnopharmacology 65: 13-19.
Scrimshaw, S. \& Hurtado, E. 1987. Rapid assessment procedures for nutrition and primary health anthropological approaches for programmes improvent. Los Angeles, UCLA.

Valle, T.L. 2002. Coleta de germoplasma de plantas cultivadas. Pp. 129-154. In: M.C.M. Amoroso; L.C. Ming \& S.P. Silva (eds.). Métodos de coleta e análise de dados em etnobiologia, etnoecologia e disciplinas correlatas. Rio Claro, Unesp.

Viertler, R.B. 1999. A idéia de "sustentabilidade cultural": algumas considerações críticas a partir da antropologia. Pp. 17-35. In: J.B. Bastos Filho; N.F.M. Amorim \& V.N. Lages (orgs.). Cultura e desenvolvimento: a sustentabilidade cultural em questão. Maceió, PRODEMA/UFAL.

Takemory, A.E.; Kupferberg, H.J. \& Miller, J.W. 1969. Quantitative studies of the antagonist of morphine by nalorphine and naloxone. Journal Pharmacology and Experimental Therapeutics 169(1): 39-49. 